\title{
Presencia del espíritu piagetiano en los lineamientos de política educativa en Bogotá
}

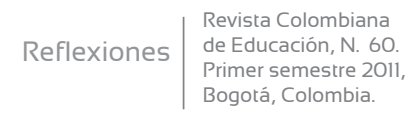

\section{//Presence of Piagetian Spirit in the Educational Policy Principles in Bogotá}

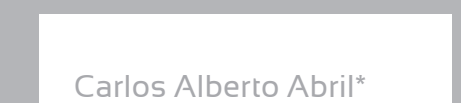

\section{Resumen}

El artículo intenta ubicar la influencia del pensamiento de Jean Piaget en la formulación de algunas de las políticas educativas de la Secretaría de Educación de Bogotá intentando demostrar la necesidad de retornar a los fundamentos teóricos que formuló para resolver algunos de los problemas que aquejan a la educación en nuestra ciudad.

\section{Abstract}

This paper aims to locate the influence of Piaget's thinking on conceptualization of some educational policies by the Secretaría de Educación in Bogotá, trying to demonstrate the need to take back the theoretical foundations to solve some of the issues facing education in our city.

\section{Palabras Clave}

Epistemología Genética, estadios del desarrollo, Psicología genética, inteligencia, estructuralismo, reorganización curricular por ciclos educativos.

\section{Keywords}

Genetic epistemology, developmental stages, genetic psychology, intelligence, structuralism, curricular reorganization by education cycles. 


\section{Introducción}

Los aportes de Jean Piaget al estudio sobre el origen del conocimiento en el ser humano son multidimensionales. Es de señalar que su contribución no se restringe a la formulación sobre los estadios del desarrollo cognitivo del niño, sino que influye en diversos campos que intentan responder a interrogantes esenciales sobre el hombre y su posibilidad de conocer; es el caso de la Psicología en general, la Psicología Educativa, la Pedagogía, la Sociología y la Biología. En cada una de estas disciplinas es posible rastrear un aporte, muchas veces determinante, de parte del pensador ginebrino.

Es necesario recordar que la versatilidad de su pensamiento, se hizo manifiesta de manera muy temprana en su vida. A los once años publicó por primera vez un artículo de carácter científico, que presagiaba el carácter sistemático de su pensamiento, y la capacidad de utilizar diversas herramientas para acceder a la explicación de situaciones aparentemente refractarias al acercamiento científico.

A continuación se realizará una lectura de los "Referentes conceptuales de la reorganización curricular por ciclos" (Rodríguez, Abel y otros, SED Bogotá: Documento de trabajo, 2008), texto que orienta la actual política educativa distrital, para así, identificar qué tan influenciados se encuentran por la propuesta piagetiana, y las implicaciones pedagógicas, didácticas y metodológicas de ese aporte.

\section{Similitud filosófica y pedagógica}

La política pública educativa en el distrito capital apunta a una transformación pedagógica de la escuela; para lograr este resultado, se ha apelado a la reorganización curricular por ciclos educativos. Es de anotar que se parte de un diagnóstico crítico de la realidad escolar: "Comprender el desequilibrio que existe en el desarrollo del proceso de enseñanza aprendizaje, implica reconocer que la escuela sigue exponiendo al educando a prácticas de enseñanza del siglo pasado, en las que las clases magistrales, el ambiente dictatorial, la desarticulación de los niveles y grados, la fragmentación del conocimiento, así como el desarrollo de mecanismos estandarizados de enseñanza que llevan a la desarticulación de la evaluación, nada tienen que ver con la forma en la que el estudiante de hoy aprende, contribuyendo a 
incrementar los problemas de convivencia y deserción escolar"(SED Bogotá, 2008, pág. 5).

Con la lectura del documento anterior, se pueden ubicar algunas de las criticas de de Piaget a la escuela tradicional, lo que lo llevó proponer, el paso de una escuela tradicional a una de carácter activa u orientada por una pedagogía científica.

En ese sentido, tanto Piaget como la directriz política, coinciden en la caracterización de una escuela autoritaria, que niega las particularidades de los estudiantes y que metodológicamente sigue orientada por principios tradicionales. Por otro lado, se cuestiona el acercamiento epistemológico al conocimiento, a través de la fragmentación de la realidad. Como respuesta a esta postura, Piaget planteó el trabajo interdisciplinario en la escuela por parte de los maestros, recomendando el modelo de su centro de epistemología genética, en el que a través de la cooperación y el aporte disciplinar de cada cual, se intenta construir una visión holística de la realidad. Esa alternativa es replicable en la escuela si se construyen las preguntas adecuadas y se diseñan las experiencias pertinentes para resolverlas.

También es relevante la referencia a la implementación de mecanismos estandarizados en la enseñanza, situación que niega la singularidad de cada estudiante e impone un proceso evaluativo común. Esa situación fue señalada por Piaget, en $i^{A}$ dónde va la educación?, como uno de los riesgos para una educación, para la libertad que tenga como eje el desarrollo personal de cada niño.

A partir de lo observado, se puede ver que existe un enfoque similar entre la propuesta de la Secretaría de Educación, y las recomendaciones que Piaget había construido como director de la Oficina Internacional de Educación; en ese sentido, puede pensarse que el pensamiento piagetiano influyó a los dirigentes educativos de nuestra ciudad.

En relación a los estudiantes, los referentes conceptuales señalan que son personas diferentes a los jóvenes del pasado, con una "forma de aprender" un tanto desconocida para los maestros, y con necesidades que se enmarcan en una sociedad fragmentada. Es de relevancia la referencia al proceso enseñanza aprendizaje, y de alguna manera, la posibilidad de transformación depende de lo que ocurra en los procesos de enseñanza y en sus agentes; es decir, los maestros y maestras.

Para Piaget era fundamental la determinación de los fines de la educación, porque teniendo claro el fin, se delimita lo pedagógico, lo didáctico y lo relacional al interior de la escuela. La política distrital plantea que la educación debe contribuir en la: "construcción de una ciudad más justa y democrática, pacífica y segura, incluyente y equitativa, en la que todos sus habitantes sean respetuosos de los derechos humanos, la diversidad y el pluralismo" (Ibíd., Pág. 4). Es claro que tal 
fin de la educación va más allá de la adquisición de conocimientos, y se enmarca en el desarrollo integral de los estudiantes. Esta propuesta coincide con la idea de Piaget, de la necesidad de que todo sujeto se reconozca como parte de un todo social.

La referencia a las etapas del desarrollo es fundamental en la propuesta por ciclos, tanto a nivel conceptual como organizativo y, aunque la teoría piagetiana no se nombra explícitamente, es posible reconocer elementos propios de ella: “...centrar los procesos de enseñanza y aprendizaje en el reconocimiento de las particularidades y necesidades de los niños, niñas y jóvenes durante las diferentes etapas de desarrollo, propiciando las condiciones que faciliten el acceso integral al conocimiento" (Ibíd., Pág. 3).

A nivel organizativo, pensar lo educativo por ciclos implica especializar un grupo de maestros en un ciclo dado y en la etapa del desarrollo correspondiente a ese ciclo, por eso se nombra como fundamental la posibilidad de constituir equipos de trabajo que garanticen la implementación a lo largo del tiempo y la actitud de autoformación respecto de los conocimientos necesarios para hacerla posible.

En lo específicamente pedagógico, la idea de desarrollo es transversal en esta propuesta política: "tiene como fundamento pedagógico, el desarrollo humano centrado en el reconocimiento de los sujetos como seres integrales, con capacidades, habilidades y dominios que deben ser desarrollados para la construcción del proyecto de vida tanto individual como social" (Ibíd., Pág. 4).

En la actitud de reconocer como sujeto a un estudiante, es de gran relevancia la identificación de sus intereses y necesidades, porque ellas son el motor motivacional para la adquisición de nuevos conocimientos y la construcción de nuevas estructuras mentales; por ello, no es extraña la invitación a que los maestros planteen nuevas aproximaciones didácticas y pedagógicas: "aprender a través de estrategias que den respuesta a sus intereses y necesidades (las de los estudiantes) y a las demandas de formación del contexto educativo" (Ibíd., Pág. 4). Idea que fue recurrente en las reflexiones de Piaget sobre el rol docente y el papel de la escuela como responsable de propiciar las condiciones formadoras para sus estudiantes.

Con lo anterior, se ha identificado una coincidencia de tipo filosófica/pedagógica entre la propuesta de Piaget y la propuesta educativa en distrito capital. 


\section{Similitud conceptual}

A continuación se intentará ubicar el vínculo conceptual con la propuesta piagetiana de los estadios del desarrollo. La concreción de la propuesta por ciclos educativos de la Secretaría de Educación es la siguiente:

ORGANIZACIÓN CURRICULAR POR CICLOS EDUCATIVOS

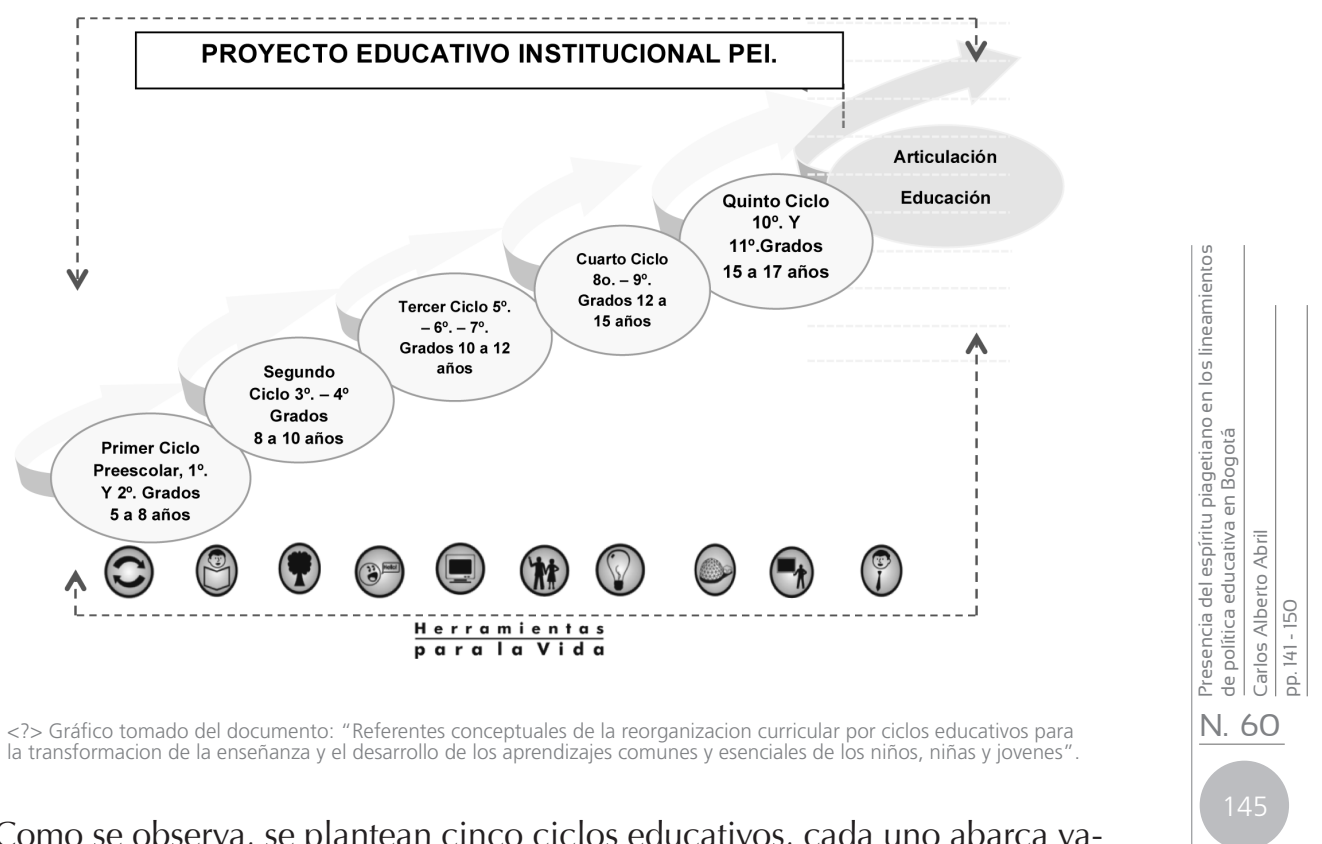

Como se observa, se plantean cinco ciclos educativos, cada uno abarca varios grados escolares, por ejemplo el tercer ciclo incluye los grados quinto, sexto y séptimo; igualmente, se señala una edad aproximada para que los niños pertenezcan a un ciclo dado, en el caso del tercer ciclo el rango de edades es entre los 10 y los 12 años.

La propuesta de Piaget plantea cuatro grandes periodos, el primero de ellos no es tomado en cuenta en la propuesta por ciclos, ya que los niños que se escolarizan ya han pasado por ese periodo, por lo cual se identifica el vínculo entre los ciclos y periodos de desarrollo a partir de la adaptación del siguiente esquema SED. 


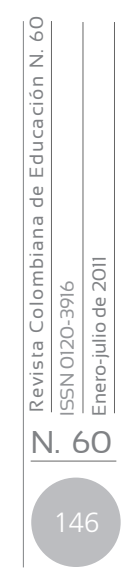

\begin{tabular}{|c|c|c|c|c|c|c|}
\hline 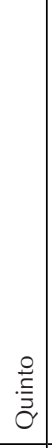 & 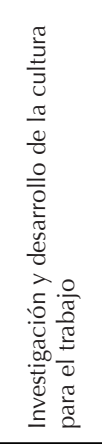 & 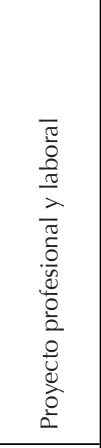 & $\begin{array}{l}0 \\
+ \\
2 \\
0 \\
- \\
-\end{array}$ & 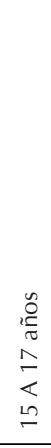 & \multirow{6}{*}{ 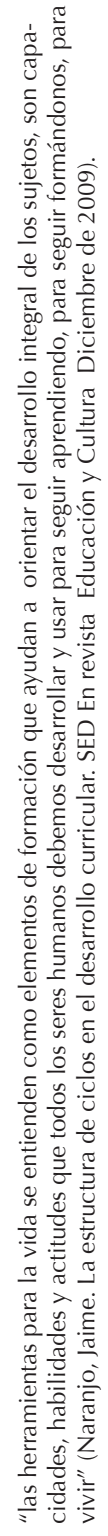 } & \multirow{2}{*}{ 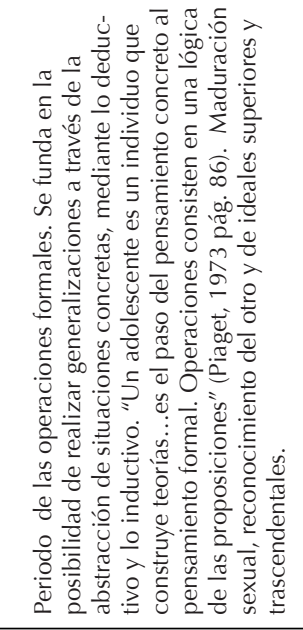 } \\
\hline $\begin{array}{l}0 \\
\frac{0}{0} \\
\text { U. }\end{array}$ & 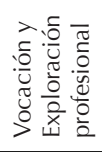 & 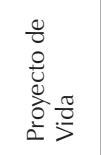 & $\begin{array}{l}8 \\
\dot{2} \\
\dot{0}\end{array}$ & 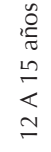 & & \\
\hline 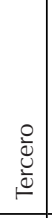 & 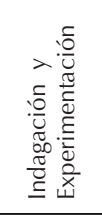 & 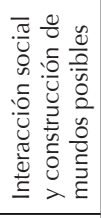 & $\begin{array}{l}i \\
i \\
0 \\
0 \\
i n \\
i n \\
\end{array}$ & 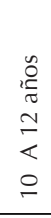 & & 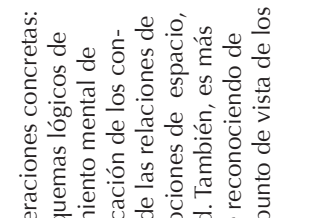 \\
\hline & 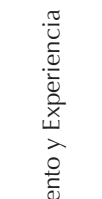 & 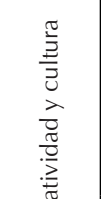 & & & & 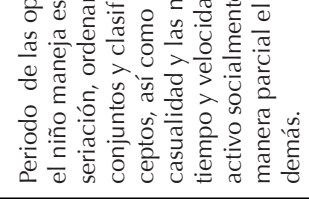 \\
\hline 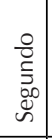 & 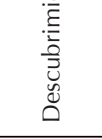 & 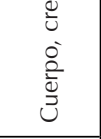 & $\begin{array}{l}\stackrel{\circ}{+} \\
\text { गे } \\
\text { in }\end{array}$ & 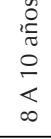 & & 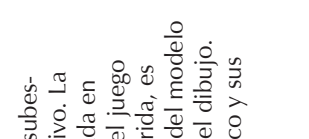 \\
\hline 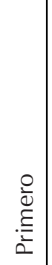 & 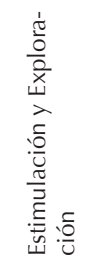 & 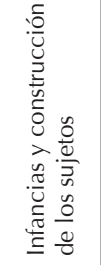 & 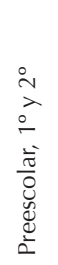 & 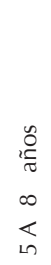 & & 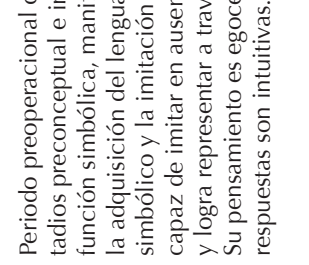 \\
\hline 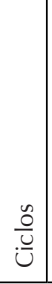 & 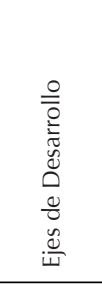 & 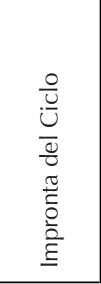 & 广 & 胥 & 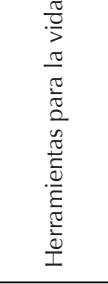 & 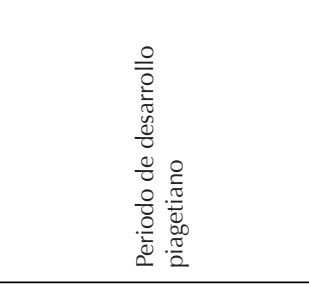 \\
\hline
\end{tabular}


Observando lo anterior, es posible establecer una relación entre la propuesta política y la teoría piagetiana. En relación al primer ciclo, el eje de desarrollo corresponde a la estimulación y exploración, ahí podemos identificar los dos componentes fundamentales de la relación pedagógica: el maestro que estimula, y el niño que explora. Por su parte, la impronta del ciclo puede identificarse con las estructuras mentales, tanto cognitivas como morales: "El desarrollo infantil vive un proceso complejo caracterizado por el surgimiento de la comunicación de los niños con su familia; su prodigiosa comprensión de las nociones tiempo y espacio; el desarrollo creativo de sus funciones psíquicas y cognitivas evidenciadas a partir de sus dibujos e iconografías; la construcción de su oralidad, sus preguntas y sus explicaciones como preámbulo para mostrar la conquista de la escritura y la lectura".(Ibíd., Pág. 12). Este primer ciclo se traslapa con el periodo pre-operacional piagetiano, en el que se privilegia la manipulación de objetos y el juego simbólico como mecanismo adaptativo del niño. Es un periodo de inteligencia práctica, en la que predomina el pensamiento egocéntrico.

En los ciclos segundo y tercero, se observa una relación de continuidad entre la construcción y el fortalecimiento de la imagen de sí en el niño, y a su vez, su vinculación a un grupo de referencia, en ese sentido hay cierta continuidad que no obstante, se delimita a nivel de la forma de acercamiento al objeto, y que contribuye desde el punto de vista organizativo. Si se recuerda la propuesta de Piaget, es este el periodo de las operaciones concretas están basadas en la experiencia y el análisis a partir de esquemas lógicos de seriación y clasificación de las situaciones por parte del niño.

En la propuesta de la SED es claro el carácter propedéutico de los ejes de desarrollo (uno como antecedente del otro): descubrimiento y experiencia en el ciclo dos, e indagación y experimentación en el tres. Es relevante también señalar cómo se va construyendo una posición más autónoma y activa de parte del niño a medida que avanza en los ciclos; es diferente descubrir y vivir una experiencia de indagar y experimentar. En el documento se señala esto de la siguiente manera para el ciclo dos: "Los procesos de enseñanza y aprendizaje estarán orientados al descubrimiento de las relaciones entre los objetos y los fenómenos que surgen mediante la interacción concreta con los objetos y la experimentación mediante la cual realizan modificaciones en sus nociones y conceptos previos, especialmente de cantidad, espacio y tiempo" (Ibíd., Pág. 14).

Respecto del ciclo tres la propuesta no puede ser más cercana a la teorización de Piaget: "En este período de vida los aprendizajes están orientados por la Indagación y la experimentación, procesos an- 
clados en las dinámicas de desarrollo de los niños y las niñas que comienzan a dominar las relaciones de proporcionalidad y conservación, sistematizan operaciones concretas, las cuales no solo se refieren a objetos reales, sino que inician un camino hacia la fantasía y la construcción de mundos posibles" (Ibíd., Pág. 16). Se ubica aquí el periodo de las operaciones concretas, en el que Piaget reconoce nuevas posibilidades para el niño: "Asistimos en cada uno de los aspectos tan complejos de la vida psíquica, tanto si se trata de la vida psíquica afectiva, de las relaciones sociales o de la actividad individual, a la aparición de nuevas formas de organización que completan los esquemas de las construcciones presentes durante el periodo precedente y les aseguran un equilibrio más estable, inaugurando también una serie ininterrumpida de nuevas construcciones" (Piaget, 1973 pág. 54).

Finalmente, los ciclos cuatro y cinco pueden relacionarse directamente con el periodo de las operaciones lógico matemáticas, pero el acento desde la propuesta está dado más a dar respuestas a situaciones de índole relacional de construcción de proyecto de vida y de fortalecimiento personal con miras a la integración social. En el ciclo cuatro se plantea: "Este ciclo es una etapa de construcción de estructuras de pensamiento, especialmente para la solución de problemas teóricoprácticos. Identificación y clasificación de prioridades de responsabilidad para la convivencia y desarrollo de la vida social. Los jóvenes de este ciclo necesitan de espacios de trabajo en grupo, para competir en equipo, estímulo al liderazgo, al trabajo solidario, a la producción de normas de comportamiento grupal" (Ibíd., Pág. 18). Es de anotar que en la propuesta de la SED se toman en cuenta además de las necesidades cognitivas, las socio afectivas, las físicas y las creativas, lo que implica un enriquecimiento de los propuesto por Piaget, a quien se le criticó su énfasis en lo cognitivo, no obstante el fundamento de la propuesta se vale del desarrollo lógico matemático propio de esa edad.

\section{Conclusión}

El acento dado a la noción de los estadios y los reparos a la propuesta teórica de Piaget en los años setenta y ochenta, sumados a la aparición de otras propuestas didácticas, propiciaron el olvido de sus aportes, o su simple incorporación como conocimiento del sentido común en la pedagogía contemporánea. Sin embargo, el análisis de algunos de sus textos y la lectura de propuestas en política educativa, demuestra que el pensamiento sobre educación y pedagogía del pensador ginebrino son más actuales que nunca. Lo contradictorio es que su lucha por construir una pedagogía orientada científicamente, 
parece estar perdida en la medida que, con la fragmentación del conocimiento, las exigencias sociales y económicas de la sociedad, la educación en general, y la pedagogía en particular, buscan soluciones inmediatistas fundadas en un acento de lo metodológico y en la mirada individual.

Algo de esto les atañe a los maestros, porque sería necesario que se atrevieran a compartir sus experiencias, a hacer equipo; a ponerse en juego en una construcción colectiva de respuestas a las exigencias actuales. No obstante, en el medio distrital existe temor frente a la evaluación y a todo lo que tenga que ver con ella, lo que incide en generar la apertura de ese tipo de espacios: respecto a la evaluación docente la profesora Turga señaló que los docentes se sienten muchas veces chantajeados, amenazados por los rectores. Ante este punto es importante el trabajo de concientización y organización con los profesores en los colegios (Prensa ADE, 30 abril 2010). El origen de esos temores puede encontrarse en el parágrafo 1 del artículo 36 del Decreto 1278 de 2002: "1. Evaluación ordinaria periódica de desempeño anual: el docente que obtenga una calificación inferior al sesenta por ciento $(60 \%)$, la cual se considera no satisfactoria, durante dos (2) años consecutivos en evaluación de desempeño, será excluido del escalafón y, por lo tanto, retirado del servicio". Situación que si es comparada con la anterior normatividad, Decreto 2277 de 1979, es lesiva para el gremio docente.

La alternativa propuesta con el presente texto es realizar una lectura interactiva de los textos piagetianos, con los avances actuales en Pedagogía, Didáctica, Psicología, con todas aquellas disciplinas que pueden decir algo sobre el ser humano, para que así, a través de la unión de la práctica pedagógica, con una actitud investigativa, se construya una educación acorde a las necesidades del siglo XXI.

Finalmente, volver a Piaget no implica saber de memoria los estadios del desarrollo que delimitó, implica ver al niño como sujeto; con intereses, necesidades y deseos, que busca ser escuchado y cuyas destrezas y habilidades sean colocadas a prueba con problemas acordes al desarrollo social y cultural de su entorno. Implica además, conocer y estudiar a profundidad los factores que delimitan el comportamiento del niño para poder así incidir sobre ellos. 


\section{Referencias}

ADE. Profesores analizan el Decreto 1278. Prensa. Recuperado el 30 de abril 2010. En: http://www.adebogota.org/index.php?option=com_ content\&view=article\&id=685: profesores-analizan-el-decreto-1278 \&catid=38: comunicados\&ltemid $=78$

Araya, V., Alfaro, M., \& Andonegui, M. (2007). Constructivismo: Orígenes y Perspectivas.

Battro, A. M. (1969). El pensamiento de Jean Piaget": psicología y epistemología. Buenos Aires: Emecé.

Cairns, R. B. \& Ornstein, P. (1986). Psicología evolutiva: una perspectiva histórica. Madrid: Alianza.

Cortada de kohan, N. (2005). Posibilidad de integración de las teorías cognitivas y la psicometría moderna interdisciplinaria. Vol.22, N.1. Recuperado el 16, mayo 2011, PP. 29-58 . En: <HTTP://WWW. SCIELO.ORG.AR/SCIELO.PHP?SCRIPT=SCI_ARTTEXT\&PID=S1668$70272005000100002 \& \mathrm{LNG}=\mathrm{ES} \& N R M=I S O>$.

Debesse, M. (1985). La infancia en la historia de la psicología. En: Tratado de psicología del niño. Gratiot A. y Zazzo R. Ediciones Morata.

Decreto 1278 de junio 19 de 2002.

Delval, J. (1997). Hoy todos son constructivistas. En: Cuadernos de Pedagogía № 257, pág. 78-84.

Flores M. C. (1996). Conmemoración Académica del Centenario del Nacimiento de Jean Piaget. Editorial Universidad Estatal a Distancia.

Hernández, R, G. (1998). Paradigmas en la psicología de la educación. Méxic: Paidós Educador.

Leahey, T. H. (2005). Historia de la psicología, 6a edición. Madrid: Prentice Hall.

Piaget J. (1974). A dónde va la educación. Barcelona: Editorial Teide. (1999). De la Pedagogía.Buenos Aires: Editorial Paidós. (1969). El nacimiento de la inteligencia en el niño. Madrid: Aguilar. Psicología y Pedagogía. (1983). Madrid: Editorial.

Seis estudio de psicología. (1973). Barcelona: Barral editores.

Rodríguez, Abel \& otros. (2008). Referentes Conceptuales de la Reorganización Curricular por Ciclos Educativos para la Transformación de la Enseñanza y el Desarrollo de los Aprendizajes Comunes y Esenciales de los Niños, Niñas y Jóvenes. Bogotá: SED.

Vasquez, A. \& Oury, F. (2001). Hacia una pedagogía del siglo XX, Madrid: Editorial Popular.

Walkerdine V. (1995). Psicología del desarrollo y pedagogía centrada en el niño: La inserción de Piaget en la educación temprana. Ediciones La Piqueta. 